\title{
Analyzing the Typology of First Graders' School Adjustment and Identifying the Predictors of Mothers' Educational Involvement
}

\author{
Yea-Ji Hong ${ }^{1}$, Yujin Jang ${ }^{2}$, Kangyi Lee ${ }^{3}$ \\ Lecturer, Department of Child Studies, Inha University, Incheon, Korea ${ }^{1}$ \\ Assistant Professor, Department of Early Childhood Education, Catholic University of Korea, Bucheon, Korea ${ }^{2}$ \\ Professor, Department of Child Development and Family Studies, Seoul National University \& Adjunct Researcher, The Research \\ Institute of Human Ecology, Seoul National University, Seoul, Korea ${ }^{3}$ \\ 초등학교 1 학년 아동의 학교적응 유형화 및 어머니의 교육참여 예측요인 검증 \\ 홍예지 ${ }^{1}$, 장유진 ${ }^{2}$, 이강이 ${ }^{3}$ \\ 인하대학교 아동심리학과 초빙교수 ${ }^{1}$, 가톨릭대학교 교육대학원 유아교육전공 조교수 ${ }^{2}$, 서울대학교 아동가족학과 교수 및 서울대학 \\ 교 생활과학연구소 겸무연구원 ${ }^{3}$
}

Objectives: The purpose of the present study was to investigate the types of school adjustment of children in the first grade and to identify the predictors of mothers' educational involvement on the children's school adjustment types.

Methods: Data were collected from 144 pairs of mothers and teachers from the Panel Study on Korean Parent Educational Involvement (PSKPEI) in 2018. Preliminary analyses were examined using descriptive statistics. Furthermore, a latent profile analysis and a three-step approach using the Mplus program were conducted to examine the typology of first graders' school adjustment and to identify the predictors of mothers' educational involvement.

Results: The major findings of this study are as follows: First, the latent profiles of first graders' school adjustment were classified into three types (mild adjustment difficulties, adequate adjustment, and highlevel adjustment). Second, the probability of being classified into each type differed according to parenting efficacy, educational support activities at home, and teacher-mother relationships among mothers' educational involvement. In particular, first graders are more likely to belong to the high-level adjustment group compared to those in the mild adjustment difficulties group when mothers have high levels of parenting efficacy, there are educational support activities at home, and there are positive teacher-mother relationships.

Conclusion: These findings empirically confirmed individual differences in first graders' school adjustment, and suggest the importance of mothers' educational involvement on their children's adjustment in their first year at school.

Keywords: school adjustment, children in the first grade, latent profile analysis, mothers' educational involvement, Panel Study on Korean Parent Educational Involvement (PSKPEI)

Corresponding Author: Yujin Jang, Assistant Professor, Department of Early Childhood Education, Catholic University of Korea, 43 Jibong-ro, Bucheon-si, Gyeongggi-do, Korea

E-mail: yjjang@catholic.ac.kr
(c)The Korean Association of Child Studies

This is an Open Access article distributed under the terms of the Creative Commons Attribution Non-Commercial License (http:// creativecommons.org/licenses/by-nc/4.0) which permits unrestricted noncommercial use, distribution, and reproduction in any medium, provided the original work is properly cited. 


\section{Introduction}

적응은 일상생활의 문제나 요구에 대처하고 관리하는 심리적 과정을 말한다(Weiten \& Dunn, 2009). 학교는 학령기 아동이 대부분의 시간을 보내는 곳으로 학교적응은 아동이 학교에서 요구하는 과제의 목표를 이해하고 성취하며, 학교생활 내 규 칙을 준수하고, 타인과의 관계 속에서 심리적인 성숙을 이루 는 과정을 의미한다(Roeser \& Eccles, 1998). 초등학교 시기의 학교적응은 이후 청소년기의 학교적응과 성인기의 사회생활 적응에도 영향을 미치고(Sturge-Apple, Davies, \& Cummings, 2010), 학교 부적응을 경험한 아동이 심리적 어려움을 겪어 부정적인 자아개념과 가치관을 형성할 수 있다(Correia \& Marques-Pinto, 2016)는 점에서 아동의 학교적응은 중요하다. 따라서 아동의 가치관, 동기, 태도 등의 형성과 관련이 있는 학 교적응(J. Chung, 2019)을 면밀히 살펴보고, 아동의 건강한 발 달과 긍정적 적응을 돕기 위한 적절한 조기 지원의 방안을 마 련하는 것이 필수적일 것이다.

초등학교 입학은 아동이 다양한 인지적, 관계적 측면의 지 식, 기술, 태도 등의 학습을 시작하는 시기다(Berns, 2015). 본 격적인 공교육 체계의 진입으로 아동기에는 유아기보다 더 높 은 수준의 사회적 규범과 학업 수행 및 또래, 교사 등 주변 타 인과의 다양한 관계 맺기 등이 요구되며 이에 이들이 경험하는 환경적 변화는 긴장과 불안을 야기하기도 한다(Jeong \& Park, 2017). 구체적으로 Goh와 Jeon (2020)은 유아교육기관에서 초 등학교로의 전이는 아동에게 도전적인 과업이자 학교적응의 위기를 경험할 가능성을 높인다고 하였다. 이에 생애주기 관점 에서 초등학교 전이를 중요하게 여기고 학령초기 아동을 중심 으로 이들의 학교적응을 심도있게 살펴볼 필요가 있다.

그런데 지금까지 선행연구(J. Chung, 2019; E. Kim, 2018; J. Y. Kim \& K. Lee, 2020; Sturge-Apple et al., 2010)는 아동의 학 교적응을 변수 중심 접근(variable-centered approach)을 적용하 여 살펴보았다. 이러한 접근은 개인 단위에서 아동의 학교적 응이 어떠한 양상을 보이는지 살펴보고, 나아가 이질적인 집 단의 특성으로 구분될 수 있음을 확인하지 못한다는 데 한계 가 있다. 이에 이 연구에서는 사람 중심 접근(person-centered approach)에 기초하여 초등학교 1학년 아동의 학교적응을 유 형화하고자 한다. 즉, 사람 중심 접근은 개인 단위에서 개별 특 성이 다양한 방식으로 결합되어 있기 때문에 전체 모집단에서 유사한 결합 형태를 보이는 개인의 이질적인 하위 집단을 분 류하고 유형화하기 위한 방법이다(Marsh, Lüdtke, Trautwein, \& Morin, 2009). 관련하여 초등학교 저학년 아동을 대상으로
국내·외 연구(Goh \& Jeon, 2020; Mindrila, 2016)가 점차 축적 되고 있다. 예를 들어, Mindrila (2016)는 6-11세 아동의 학교 행동이 안정적 적응형, 경미한 적응 어려움형, 기능적으로 손 상된 적응형으로 구분되고, Goh와 Jeon (2020)은 학교생활 적 응, 학업 수행, 또래 관계 및 교사 관계로 살펴본 초등학교 1학 년 아동의 학교적응이 낮은 수준, 중간 수준 및 높은 수준으로 구분된다고 하였다. 그러나 사람 중심 접근에 기초하여 초등 학교 저학년 아동의 학교적응을 살펴본 국내 연구는 긍정적 학교적응 지표에, 국외 연구에서는 아동이 학교에서 보이는 문제행동 즉, 부정적 학교적응 지표에 초점을 맞추어 학교적 응의 단편적 측면을 살펴보았다는 데 한계가 있다. 이에 학교 환경으로의 전이를 경험한 국내 초등학교 1 학년 아동을 대상 으로 긍정적 지표와 부정적 지표를 아울러 학교적응의 통합적 측면을 살펴보고, 이에 따라 아동의 학교적응의 각 유형별 특 성을 사람 중심 접근을 통해 확인할 필요가 있다.

자녀의 학령기 진입은 아동뿐만 아니라 부모에게도 학부 모로서 다양한 행사 참여 및 교육적 기여 등 다양한 역할이 요 구되고, 교육 정보를 수집하는 등 참여 기대가 확대되는 중요 한 사건이다(Berns, 2015; Y.-J. Hong \& Lee, 2020; Jung, Hong, $\&$ Lee, 2019). 따라서 이 연구에서는 아동의 학교적응을 유형 화하고, 나아가 학교적응 유형화에 미치는 미시체계와 중간체 계 내 변인을 Bronfenbrenner의 생태학적이론(Bronfenbrenner, 1979)에 근거하여 다면적이고, 체계적으로 검토하고자 한다. 아동의 발달에는 가정, 학교 환경과 같은 미시체계의 독립적 인 영향뿐만 아니라 미시체계 간의 상호작용인 중간체계가 중 요한 역할을 한다(Bronfenbrenner, 1979). 이에 미시체계로서 가정 내 부모 관련 요인 중 어머니의 양육역량, 자녀교육에 대 한 심리적 기대를, 중간체계로는 학교 내 교육의 3 주체로서 아 동, 학부모, 교사 간의 상호작용을 아우르는 어머니의 교육 참 여 즉, 가정 내 교육지원 활동, 사교육 지원 및 교사-학부모 관 계를 Hoover-Dempsey와 Sandler (1997)의 학부모 교육 참여 신 념체계에 근거하여 동시에 고려하고자 한다. 아동의 인구사회 학적 또는 개인 변인에 따른 학교적응 유형 간의 차이를 설명 한 기존 연구의 한계를 넘어 학령초기 아동이 마주하는 새로 운 환경에서의 어려움을 극복하고 안정적으로 학교 환경에 적 응하도록 가정의 맥락 중 학부모로부터의 적절한 보호 요인을 찾으려는 시도가 필요할 것이다. 특히 학부모로서 자녀의 교 육 참여를 이해하는 것은 아동의 학교적응을 돕기 위한 주요 지표가 될 수 있다. 따라서 학부모의 교육 참여를 체계적으로 확인하고, 아동의 학교적응 유형에 미치는 영향을 확인한다면 유형별 차별적인 대안을 마련하는 데에도 도움이 될 것이라 
예측할 수 있다.

Hoover-Dempsey와 Sandler (1997)는 학부모가 자녀의 학교 교육에 참여하게 되는 예측요인으로 '자녀의 학교적응에 도움 을 줄 수 있다는 부모효능감(parental sense of efficacy for helping children succeed in school)'과 '부모역할구성(parental role construction)'의 두 가지 신념체계를 제시하였다. 첫 번째 신념 인 부모효능감은 부모가 자녀의 학교 교육에 참여함으로써 자 녀의 학습과 학업성취에 긍정적인 영향을 미칠 것이라는 믿음 으로 정의한다(Hoover-Dempsey \& Sandler, 1997). 이는 자녀교 육에만 초점을 맞추어 자녀의 학교 교육이나 학업 성취 향상 에 미치는 부모효능감(Anderson \& Minke, 2007) 또는 여기서 더 나아가 일반적 양육 능력으로서의 부모효능감(Shumow \& Lomax, 2002)으로 나누어 볼 수 있으며, 이에 이 연구에서는 광의의 관점에서 자녀의 학교적응에 도움을 줄 수 있는 부모 효능감을 어머니의 양육역량과 자녀교육에 대한 심리적 기대 를 통해 확인하고자 한다.

양육역량은 자녀 양육을 위한 개인의 단편적인 지식과 기 능, 양육에 대한 가치관과 같은 내적요인 및 자녀의 성장에 따 라 실제로 부모 역할을 수행하기 위한 잠재력을 아우르는 포 괄적인 개념이다(Jang \& Yun, 2014). 학령초기 아동의 학교적 응에 미치는 어머니의 양육 관련 특성으로 양육태도(C. I. Kim \& Kwon, 2018; Min, 2018), 양육민감성 및 양육효능감(Woo \& Shim, 2019) 등을 확인할 수 있지만 대부분 양육 특성의 세부 적 측면에 주목하였다. 이에 어머니가 수행하는 역할과 적응 의 지표로서 지식적, 정의적, 실천적 양육 특성을 아우르는 종 합적인 양육역량을 고려할 필요가 있다. 특히 양육역량은 개 인의 내적 특성 및 개인이 처한 사회적 환경에 따라 상이하게 발현된 가능성이 있으므로(Jung et al., 2019), 자녀의 초등학교 입학을 경험하는 어머니의 양육역량이 아동의 학교적응 유형 에 미치는 영향을 확인할 필요가 있다. 유사한 맥락에서 Jung 등(2019)은 초등학교 전이기 자녀를 둔 어머니의 양육역량의 변화 유형 중 하위유지집단과 중상위유지집단 간 및 급감소 집단과 중상위 유지집단 간에 자녀의 학교적응에 통계적으로 유의한 차이가 있음을 보였다.

나아가 자녀교육에 대한 심리적 기대를 부모효능감을 대리 하는 요인으로써 양육역량과 함께 살펴보고자 한다. 부모가 자녀교육에 대해 갖는 심리적 기대에 따라 자녀의 학교적응 수준이 달라질 수 있기 때문이다. 자녀교육에 대한 심리적 기 대는 자녀의 학업에 대한 불안 및 성취지향적 특성을 반영하 여 이 연구에서는 성공에 대한 신념, 부모-자녀 동일시 및 심 리적 위축을 통해 살펴보고자 한다. 구체적으로 부모가 이루
지 못한 학업 목표를 자녀가 대신 이루어 주길 바라는 기대 심 리, 자녀의 성공적인 학교적응 또는 학업성취를 곧 자신의 성 취로 동일시하거나(Han, 2008; M.-K., Lee, 2007), 자녀의 성취 로부터 자신의 자존감을 대신하려는 경향이 높을수록 자녀에 대한 통제적 양육태도가 높음(Seol, Kyeong, \& Park, 2015)을 알 수 있다. 이를 근거로 학령초기 자녀를 둔 어머니에게 자녀 의 학업에 대한 적절한 기대 수준을 설정하는 것이 중요하며, 그렇지 않을 경우 부모-자녀 관계를 악화시키고, 궁극적으로 아동의 학교적응을 위협하는 요인이 될 것이라 추론해 볼 수 있다.

다음으로 학부모의 교육 참여를 예측하는 두 번째 신념인 부모역할구성은 자녀의 교육과 관련하여 부모로서 해야 할 일 에 대한 신념 및 그러한 신념에 따르는 부모의 행동 패턴으로 정의한다(Hoover-Dempsey et al., 2005). 이에 이 연구에서는 아 동, 부모, 교사 간의 상호작용을 고려한 어머니의 가정 내 교 육지원 활동, 사교육 지원 및 교사-학부모 관계를 관련 변인으 로 상정하여 초등학교 1학년 아동의 학교적응에 미치는 영향 을 살펴보고자 한다. 먼저 학부모 교육지원은 자녀의 학업 수 행 지원을 위한 학부모가 제공하는 활동을 말하며, 이는 자녀 의 발달과 학업 성취에 긍정적인 영향을 미치는 일련의 활동 뿐만 아니라 자녀와의 상호작용을 포함한다(Chun \& Chun, 2016). 관련하여 취학 전 어머니의 학습 관여 행동이 자녀의 학교준비도에 정적 상관을 보인다(S. H. Lee \& Hwang, 2014). 특히 중·고등학생에 비해 초등학생의 경우에 부모의 교육지원 행동이 자신에게 더 긍정적인 도움된다(Chun \& Chun, 2016). 따라서 이 연구에서는 학부모의 교육지원 활동을 가정 내의 교육지원 활동과 외부 기관을 통한 사교육 지원으로 확인하고 자 한다. 특히 가정 내에서 자녀의 교육지원을 위해 학습에 적 절한 환경을 제공하거나 학습 분위기를 조성하고, 직접적으로 학습을 지도하며 다양한 교육 관련 정보를 수집하고, 경험을 제공하는 등 어머니가 자녀 교육 지원을 위해 주체적인 역할 을 한다면 학령초기 자녀의 학교적응에 긍정적인 영향을 미칠 것이라 예측할 수 있다. 또한 자녀의 교육적 성취에 대한 높은 관심과 교육열을 보이는 우리나라의 문화적 맥락에서 자녀를 위한 높은 교육 투자에 대한 인식은 강력한 동기가 되어 높은 사교육 투자로 실현되며(M.-K. Lee, 2007), 이에 어머니의 학 령초기 사교육 지원이 아동의 학교적응에 미치는 영향을 추가 적으로 살펴볼 필요성이 제기된다.

마지막으로 교사-학부모 관계를 통해 부모역할구성을 확 인할 수 있으며, Clarke, Sheridan과 Woods (2009)는 교사-학부 모 관계를 교사와 학부모의 협력 행동과 관련된 개인의 정서 
적 특성으로 보았다. 구체적으로 부모참여가 유치원생과 초등 학교 1학년생의 긍정적 학업 성취와 사회적 유능성과 관련이 있다고 한 연구(Kohl, Lengua, \& McMahon, 2000), 유치원부터 초등학교 4학년 자녀를 둔 부모의 교사에 대한 신뢰가 학부모 의 학교 참여와 아동의 학교 행동을 유의하게 예측한다는 연 구(Santiago, Garbacz, Beattie, \& Moore, 2016), 교사와 학부모 관계에 대한 교사의 인식이 아동의 사회적 적응에 정적인 관 련이 있고, 외현화 문제행동에 부적인 관계가 있다는 연구(E. M. Kim, Sheridan, Kwon, \& Koziol, 2013)가 있다. 이를 통해 신 뢰, 민감성 및 평등한 관계에서 구축되는 교사와 학부모의 상 호 간 협력이 아동이 경험하는 심리적, 행동적 역기능을 보호 하는 완충적 역할을 할 것이라 기대한다.

이상의 논의를 바탕으로 이 연구에서는 초등학교 1 학년 아 동의 학교적응의 유형을 확인하고, Hoover-Dempsey와 Sandler (1997)의 학부모의 교육 참여 예측요인에 근거하여 어머니의 양육역량, 자녀교육에 대한 심리적 기대, 가정 내 교육지원 활 동, 사교육 지원 및 교사-학부모 관계가 아동의 학교적응 유형 에 미치는 영향을 체계적으로 확인하고자 한다. 이에 따라 도 출된 구체적인 연구문제는 다음과 같다.

\section{연구문제 1}

초등학교 1학년 아동의 학교적응은 몇 개의 유형으로 구분되 며, 유형별 특성은 어떠한가?

\section{연구문제 2}

초등학교 1 학년 자녀의 학교적응 유형에 미치는 어머니의 교 육 참여 예측요인의 영향력은 어떠한가?

\section{Methods}

\section{연구대상}

이 연구는 서울대학교 학부모정책연구센터에서 구축한 학 부모교육참여패널(Panel Study on Korean Parent Educational Involvement [PSKPEI]) 자료(Center for Family-School Partnership Policy Research at SNU, 2019)를 사용하였다. 학부 모교육참여패널은 자녀의 성장에 따라 학부모의 역할과 교육 참여의 종단적 변화를 확인하고자 다음과 같은 자료수집의 절 차를 진행하였다. 2016년 교육통계연보에 따라 서울, 경기 및 인천 지역의 초등학교 1 학년 학생의 수에 근거하여 할당 표집
을 실시하였고, 자녀의 성비와 맞벌이 가족을 고려하여 균등 비율 표집을 실시하였다. 입학 전 1차, 1학년 여름에 2 차 및 2 학년 여름에 3차순으로 조사가 진행되었다. 구체적으로 2017 년 3월에 첫 자녀를 초등학교에 입학시킨 학부모 368명을 대 상으로 입학 전 1차 조사를, 같은 해 8월에 학부모 243명을 대 상으로 2차 조사(2017년)를 실시하였으나(표본 유지율 66\%), 165 명의 데이터를 추가로 수집하여 2차 조사에는 최종적으로 425 명이 설문에 참여하였다. 2 차 조사부터는 담임교사에 의 해 아동의 학교적응을 확인하는 문항이 추가되어 초등학교 1 학년 아동의 학교적응을 확인할 수 있었다. 이에 이 연구에서 는 2 차 조사 자료 중 해당 연구 변인에 학부모와 교사가 모두 응답한 자료만을 최종적으로 선택하여 총 144 쌍의 어머니 및 교사의 응답을 분석에 포함하였다.

연구참여자의 인구사회학적 특성은 다음과 같다. 아동의 성별은 남아 $43.8 \%$, 여아 $56.3 \%$ 이다. 어머니의 연령은 36 세 이상 40 세 이하가 $56.2 \%$ 로 가장 많았으며, 35 세 이하 $23.6 \%$, 41세 이상 45 세 이하 $16.1 \%, 46$ 세 이상 50 세 이하 $4.2 \%$ 순이 다. 어머니의 교육수준은 4년제 대학교 졸업 $59.0 \%, 2$-3년제 대학 졸업 $26.4 \%$, 고등학교 졸업 $13.2 \%$, 대학원 졸업 $1.4 \%$ 순 이고, 취업여부는 미취업모 $57.6 \%$, 취업모 $42.4 \%$ 이다. 월평 균 가구소득은 400 만원 이상 500 만원 미만의 비율이 $30.6 \%$ 로 가장 높았고, 300 만원 이상 400 만원 미만(28.5\%), 500만원 이 상 600만원 미만(11.1\%), 600만원 이상 700만원 미만(11.1\%), 200 만원 이상 300 만원 미만(11.1\%)순이다.

\section{연구도구}

\section{학교적응}

초등학교 1학년 아동의 학교적응은 Hightower 등(1986)이 개발한 교사용 아동평정척도(T-CRS)를 H. Chung (2002)이 우리나라 초등학교 1-6학년 아동을 대상으로 타당화 과정 을 거친 척도로 측정되었다. 학교적응 척도는 외현화 문제 (acting-out problems), 수줍음/불안(shyness/anxiety) 및 학습문 제(learning problems)의 세 개의 부정적 학교적응 지표와 좌절 인내(frustration tolerance), 자기주장적 사회기술(self-assertive social skills), 과제지향(task orientation) 및 또래관계기술(peer social skills)의 네 개의 긍정적 학교적응 지표로 7 개의 하위요 인 총 38문항으로 구성된다. 구체적으로 외현화 문제는 아동 의 공격적이거나 산만한 행동을 포함하는 것으로 "침착하지 못하고 가만히 앉아 있기 힘들어한다.” 등 6 문항, 비사회적이 
거나 우울, 정서적 문제를 일컫는 수줍음/불안은 "불안하고 걱 정이 많다.” 등 6문항, 학업과 관련된 문제를 포함하는 학습문 제는 “교사의 지시를 따르는데 어려움이 있다.” 등 6 문항으로 구성된다. 다음으로 좌절 상황에서의 인내할 수 있음을 의미 하는 좌절인내는 "일이 자기 뜻대로 되지 않을 수 있다는 것 을 받아들인다.” 등 5문항, 사회적 관계 속에서 자기주장을 드 러낼 줄 아는 것을 뜻하는 자기주장적 사회기술은 "자신의 생 각을 적극적으로 표현한다.” 등 5문항으로 구성된다. 또한 아 동의 과제 지향적 특성을 의미하는 과제지향은 “주어진 과제 를 완수한다.” 등 5문항, 또래와의 원만한 관계를 일컫는 또래 관계기술에는 "또래에게 친절하다." 등 5 문항이 포함된다. 모 든 문항은 6점 Likert 척도(전혀 그렇지 않다[1] 매우 그렇다 [6])로 교사가 응답하였으며, 각 변인의 평균 점수를 산출하여 점수가 높을수록 해당 하위요인의 수준이 높음을 의미한다. 신뢰도 계수 Cronbach's $\alpha$ 는 외현화 문제 .77, 수줍음/불안 .83, 학습문제 .78, 좌절인내 .72, 자기주장적 사회기술 .83, 과제지 향.81, 또래관계기술 .69다.

\section{양육역량}

양육역량은 K.-S. Chung과 Choi (2013)가 개발한 척도를 K.-S. Chung, Park과 Cha (2016)가 단축화한 것을 사용하였으며, 9개 의 하위요인, 총 27 개의 문항으로 구성된다. 자녀발달 특징 및 욕구이해 3 문항, 부모-자녀 관계이해 3 문항, 건강한 부모관 갖 기 3 문항, 자녀 삶과 양육방향 목표 설정 3 문항, 인내심 갖기 3 문항, 민주적 양육 3 문항, 반응적·공감적 양육 3 문항, 자녀생 애 진로개발 3 문항 및 발달.학습 지원환경 제공 3 문항으로 구 성된다. 모든 문항은 5점 Likert 척도(전혀 그렇지 않다[1] 매 우 그렇다[5])로 어머니가 응답하였으며, 각 변인의 평균 점수 를 산출하여 점수가 높을수록 어머니의 양육역량이 높음을 의 미한다. 신뢰도 계수 Cronbach's $\alpha$ 는 .89다.

\section{자녀교육에 대한 심리적 기대}

자녀교육에 대한 어머니의 심리적 기대는 Shim (2003)이 개발 한 심리적 지원을 통한 교육지원 활동 척도로 측정되었다. 이 척도는 3 개의 하위요인, 총 12 개의 문항으로 구성된다. 교육 을 통한 성공에 대한 신념 5 문항, 부모-자녀 동일시 4 문항 및 심리적 위축 3 문항으로 각각 구성되며, 교육을 통한 성공에 대 한 신념 중 3 개의 문항은 해석의 일관성을 위해 역코딩을 실시 하였다. 모든 문항은 5점 Likert 척도(전혀 그렇지 않다[1] 매
우 그렇다[5])로 어머니가 응답하였다. 각 변인의 평균 점수를 산출하여 점수가 높을수록 자녀교육에 대한 어머니의 심리적 기대가 높음을 의미한다. 신뢰도 계수 Cronbach's $\alpha$ 는 .75다.

\section{가정 내 교육지원 활동}

가정 내 교육지원 활동은 Shim (2003)이 개발한 척도로 측정 되었다. 이 척도는 9 개의 하위요인 총 23 문항으로 구성된다. 학습분위기 조성 3 문항, 학습지도 5 문항, 생활통제 4 문항, 시 간통제 3 문항, 정보수집 4문항, 문화적 경험 4문항이며, 학습 지도 중 2 문항은 해석의 일관성을 위해 역코딩을 실시하였다. 모든 문항은 5점 Likert 척도(전혀 그렇지 않다[1] 매우 그렇 다[5])로 어머니가 응답하였다. 각 변인의 평균 점수를 산출 하여 점수가 높을수록 어머니가 가정에서 수행하는 자녀를 위한 교육지원 활동의 수준이 높음을 의미한다. 신뢰도 계수 Cronbach's $\alpha$ 는 .86이다.

\section{사교육 지원}

사교육 지원은 Shim (2003)이 개발한 학교 외 교육을 통한 교 육지원 활동 척도로 측정되었다. 원척도는 5 개의 문항으로 구 성되나 이 연구에서는"음악, 미술, 체육 등 예체능 위주의 사 교육을 시킨다."와 “영어, 국어, 수학 등 학습 위주의 사교육을 주로 시킨다."의 2 개의 항목을 추가하여 총 7 개의 문항으로 사 교육 지원을 확인하였다. 모든 문항은 5점 Likert 척도(전혀 그 렇지 않다[1] 매우 그렇다[5])로 어머니가 응답하였다. 각 변 인의 평균 점수를 산출하여 점수가 높을수록 어머니가 자녀를 위해 제공하는 사교육 지원의 수준이 높음을 의미한다. 신뢰 도 계수 Cronbach's $\alpha$ 는 .61다.

\section{교사-학부모 관계}

교사-학부모 관계는 $\operatorname{Lim}(2001)$ 이 개발한 척도를 사용하였다. 이 척도는 학생의 교육활동과 관련된 학부모의 태도와 행동에 대한 교사의 인식을 측정한 것으로 자녀교육에 대한 관심과 열성, 교육활동 지원, 자녀지도, 교사에 대한 믿음과 존중의 정 도 등을 포함하여 총 10 문항으로 구성된다. 모든 문항은 5점 Likert 척도(전혀 그렇지 않다[1] 매우 그렇다[5])로 교사가 응답하였다. 각 변인의 평균 점수를 산출하였으며, 점수가 높 을수록 교사가 지각하는 교사-학부모 관계가 긍정적임을 의 미한다. 신뢰도 계수 Cronbach's $\alpha$ 는 .95다. 


\section{자료분석}

초등학교 1학년 아동의 학교적응을 유형화하기 위해 Mplus 8.0 (Muthén \& Muthén, 1998-2002) 프로그램을 사용하여 잠재 프로파일 분석(latent profile analysis)을 실시하였다. 잠재집단 의 수를 결정하기 위해 정보준거지수, 분류의 질, 모형비교 검 증 및 집단 내 분류비율의 통계적 기준을 사용하였다. 정보준 거지수는 $\mathrm{AIC}, \mathrm{BIC}, \mathrm{sBIC}$ 를 확인하고, 이는 세 개의 값이 작을 수록 모형의 합치도가 좋음을 의미한다. 분류의 질은 Entropy 값을 확인하여 0 에서 1 사이의 값 중 대략 . 8 이상이면 분류의 질이 양호함을 의미한다(Muthén, 2004). 다음으로 모형비교 검증은 Lo-Mendell-Rubin adjusted Likelihood Ratio Test (LMR) 와 Bootstrap Likelihood Ratio Test (BLRT)를 살펴보았다. 두 검 증 모두 잠재집단이 $\mathrm{k}$ 개인 모형을 지지하기 위해 잠재집단이 $\mathrm{k}-1$ 개인 모형이 기각되는지 p값의 유의도를 통해 검증하는 방 법이다. 마지막으로 집단 내 분류비율은 개별 집단의 크기가 전체표본의 $5 \%$ 미만이거나 25 명 이하일 경우 우연히 발생한 잠재집단일 가능성이 있다(Berlin, Williams, \& Parra, 2014)는 기준을 고려하였다. 이와 같은 통계적 기준을 근거로 초등학 교 1학년 아동의 학교적응을 유형화하였다.

다음으로 초등학교 1 학년 아동의 학교적응 유형에 미치 는 예측요인의 영향력을 검증하기 위해 Vermunt (2010)의 3단 계 접근법(3-step approach)을 적용하였다. 지표 변인뿐만 아니 라 보조 변인이 분석에 포함될 때 잠재집단 분류의 변화를 최 소화해야할 필요가 있다(Lanza, Tan, \& Bray, 2013). 이에 잠재 프로파일에 미치는 오분류의 가능성을 통제하고 분석하는 3 단계 접근법을 다음의 순서대로 적용하였다. 1 단계에서는 잠 재집단 지표를 이용해 기본 잠재집단을 추정하고, 2 단계에서 는 1 단계에서 얻어진 잠재집단 사후분포를 이용해 가장 확률 이 높은 변인을 생성하며, 3단계에서는 분류의 오류를 고려한 상태에서 보조 변인이 2 단계에서 생성된 집단의 분류에 미치 는 영향의 차이를 알아본다(Asparouhov \& Muthén, 2014). 분 석 시 발생하는 결측치 처리를 위해서는 완전정보최대우도법 (full information maximum likelihood [FIML])을 이용하였다.

\section{Results}

\section{주요 변인의 기술통계}

주요 변인의 기술통계치는 Table 1 과 같다. 변인의 점수 범위
(Range), 평균값 $(M)$ 과 표준편차 $(S D)$ 를 통해 데이터의 특성 을 살펴보았다. 초등학교 1학년 아동의 학교적응은 6점 리커 트 척도로 측정되었고, 각 하위요인의 평균을 살펴보면 외현 화 문제 $2.16(S D=.87)$, 수줍음/불안 $1.95(S D=.91)$, 학습문 제 $1.80(S D=.78)$, 좌절인내 $4.57(S D=.75)$, 자기주장적 사회 기술 $4.63(S D=.94)$, 과제지향 $4.58(S D=.87)$ 및 또래관계기 술 $4.03(S D=.63)$ 이다. 이는 초등학교에 입학한 후 아동이 외 현화 문제, 수줍음/불안 및 학습문제의 부정적 학교적응 지표 에서 1 에서 2 점대의 비교적 낮은 점수를 보이고, 좌절인내, 자 기주장적 사회기술, 과제지향 및 또래관계기술의 긍정적 학교 적응에는 4점 이상의 비교적 높은 점수를 보이는 것으로 나타 났다. 또한 아동의 학교적응 유형의 예측요인은 5점 리커트 척 도로 측정되었고, 변인의 평균은 양육역량 $3.89(S D=.32)$, 자 녀교육에 대한 심리적 기대 $2.84(S D=.61)$, 가정 내 교육지원 활동 $3.38(S D=.48)$, 사교육 지원 $2.92(S D=.62)$, 교사-학부모 관계 $4.33(S D=.61)$ 으로 어머니의 양육역량, 가정 내 교육지 원 활동뿐만 아니라 교사가 지각한 교사-학부모 관계가 3에서 4점대의 점수를 보이고, 어머니의 자녀교육에 대한 심리적 기 대와 사교육 지원은 2 점대의 점수를 보였다. 나아가 주요 변인 의 왜도(skeness)와 첨도(kurtosis)가 적정한 값을 보여(왜도 < 2, 첨도 < 4 ), 자료가 다변량 정규성을 충족시키는지 확인하였다 (S. Hong, Malik, \& Lee, 2003).

\section{학교적응 유형 및 유형별 특성}

초등학교 1학년 아동의 학교적응을 유형화하기 위해 시점별 잠재집단의 수를 증가시키면서 모형을 비교한 결과는 Table 2 와 같다. 잠재집단의 수가 증가할 때 정보준거지수인 $\mathrm{AIC}$, $\mathrm{BIC}$ 및 SABIC값이 지속적으로 감소하였고, 2 개에서 3 개로 증 가하는 지점에서 3 개에서 4 개로 증가하는 지점보다 더 가파 른 감소를 보였다. Entropy 값 역시 지속적으로 감소하였지만 모든 잠재집단의 수에서 .80이상으로 나타나 양호한 분류의 질을 보였다. 다음으로 모형의 적합도의 비교검증인 LMR은 4 개일 경우부터는 유의하지 않았으며, BLRT는 잠재집단의 수 를 4개까지 증가시켜도 계속 유의하였다. 통계적 기준과 더불 어 해석의 가능성을 종합적으로 고려하여 이질적인 잠재집단 의 수를 선택해야할 필요(McCrae, Chapman, \& Christ, 2006) 에 따라 초등학교 1학년 아동의 학교적응 유형은 잠재집단의 수가 3 개일 때 가장 적절하다고 보았으며, 이후의 분석은 3 개 집단모형을 기초로 하였다.

초등학교 1학년 아동의 학교적응의 유형별 특성은 Table 3 
Table 1

Descriptive Statistics

\begin{tabular}{|c|c|c|c|c|c|c|}
\hline & Variables & Range & $M$ & $S D$ & Skewness & Kurtosis \\
\hline \multirow[t]{7}{*}{ School adjustment } & Acting-out problems & $1.00 \sim 4.33$ & 2.16 & .87 & .68 & -.44 \\
\hline & Shyness/anxiety & $1.00 \sim 5.33$ & 1.95 & .91 & 1.07 & .89 \\
\hline & Learning problems & $1.00 \sim 4.20$ & 1.80 & .78 & 1.00 & .53 \\
\hline & Frustration tolerance & $1.80 \sim 6.00$ & 4.57 & .75 & -.92 & 1.45 \\
\hline & Self-assertive social skills & $1.80 \sim 6.00$ & 4.63 & .94 & -1.12 & .94 \\
\hline & Task orientation & $1.00 \sim 6.00$ & 4.58 & .87 & -1.09 & 1.62 \\
\hline & Peer social skills & $2.00 \sim 5.60$ & 4.03 & .63 & -.53 & .60 \\
\hline \multicolumn{2}{|c|}{ Parenting efficacy } & $2.56 \sim 5.00$ & 3.89 & .32 & -.43 & 2.23 \\
\hline \multicolumn{2}{|c|}{ Psychological expectations for children's education } & $1.33 \sim 4.50$ & 2.84 & .61 & -.27 & -.15 \\
\hline \multicolumn{2}{|c|}{ Educational support activities at home } & $2.22 \sim 4.30$ & 3.38 & .48 & -.15 & -.33 \\
\hline \multicolumn{2}{|c|}{ Private education offering } & $1.43 \sim 4.00$ & 2.92 & .62 & -.39 & -.54 \\
\hline \multicolumn{2}{|c|}{ Positive teacher-mother relationships } & $2.00 \sim 5.00$ & 4.33 & .61 & -1.01 & 1.49 \\
\hline
\end{tabular}

Table 2

Model Fit and Classification Ratio According to the Number of Latent Profiles

\begin{tabular}{|c|c|c|c|}
\hline Number of model & 2 & 3 & 4 \\
\hline AIC & 1970.625 & 1798.541 & 1743.358 \\
\hline BIC & 2035.961 & 1887.636 & 1856.210 \\
\hline Entropy & .954 & .910 & .871 \\
\hline LMR & $p<.01$ & $p<.05$ & $p>.05$ \\
\hline Group $1 n(\%)$ & $111(77.1)$ & $17(11.8)$ & $27(18.8)$ \\
\hline Group $2 n(\%)$ & 33 (22.9) & $47(32.6)$ & $52(36.1)$ \\
\hline Group $3 n(\%)$ & & $80(55.6)$ & $52(36.1)$ \\
\hline Group $4 n(\%)$ & & & $13(9.0)$ \\
\hline
\end{tabular}

Note. $N=144$. AIC = akaike information criterion; BIC = bayesian information criterion; SABIC = sample-size adjusted bayesian information criterion; LMR = Lo-Mendell-Rubin test; BLRT = Bootstrap Likelihood Ratio Test.

과 같으며, 유형별 형태는 Figure 2와 같다. 첫 번째 유형은 부 정적 학교적응 지표인 외현화 행동, 수줍음/불안 및 학습문제 가 긍정적 학교적응 지표인 좌절인내, 자기주장적 사회기술, 과제지향 및 또래관계기술보다 낮아 ‘경미한 적응 어려움형'이 라 명명하였고, 이는 전체의 $11.8 \%$ 를 차지하였다. 두 번째 유 형은 외현화 문제, 수줍음/불안 및 학습문제의 경우 2점에서 3 점대로 비교적 낮은 반면, 좌절인내, 자기주장적 사회기술, 과 제지향 및 또래관계기술은 4점에서 4.5점대로 비교적 높아 안 정적인 학교적응을 보이는 ‘안정적 적응형’이라 명명하였으며, 이는 전체의 $32.6 \%$ 를 차지하였다. 마지막 유형은 외현화 문제, 수줍음/불안 및 학습문제의 경우 2점 미만으로 세 유형 중 점
수가 가장 낮고, 좌절인내, 자기주장적 사회기술, 과제지향 및 또래관계기술은 4점 후반에서 5점이상으로 세 유형 중 점수가 가장 높아 높은 수준의 학교적응을 보이는 ‘고수준 적응형’이 라 명명하였으며, 이는 전체의 $55.6 \%$ 를 차지하였다.

\section{학교적응 유형의 예측요인}

초등학교 1 학년 아동의 학교적응 유형에 미치는 예측요인 의 영향력을 확인하기 위해 3 단계 접근법으로 분석한 결과는 Table 4와 같다. 유형 간 비교를 위해 한 유형을 준거집단으로 설정하여 다른 유형에 미치는 영향력을 비교 검증하였다. 먼 
Table 3

Estimates of Latent Means: Comparison According to Each Latent Profile Type

\begin{tabular}{|c|c|c|c|c|c|c|c|}
\hline & $\begin{array}{c}\text { Acting-out } \\
\text { problems }\end{array}$ & $\begin{array}{c}\text { Shyness/ } \\
\text { anxiety }\end{array}$ & $\begin{array}{l}\text { Learning } \\
\text { problems }\end{array}$ & $\begin{array}{c}\text { Frustration } \\
\text { tolerance }\end{array}$ & $\begin{array}{c}\text { Self-assertive } \\
\text { social skills }\end{array}$ & $\begin{array}{c}\text { Task } \\
\text { orientation }\end{array}$ & $\begin{array}{c}\text { Peer } \\
\text { social skills } \\
\end{array}$ \\
\hline Group (\%) & $M(S E)$ & $M(S E)$ & $M(S E)$ & $M(S E)$ & $M(S E)$ & $M(S E)$ & $M(S E)$ \\
\hline 1 & 3.50 & 3.46 & 3.40 & 2.99 & 2.78 & 2.98 & 3.03 \\
\hline Mild-adjustment difficulties (11.8\%) & $(.19)^{\mathrm{a}}$ & $(.32)^{\mathrm{a}}$ & $(.18)^{\mathrm{a}}$ & $(.22)^{\mathrm{a}}$ & $(.34)^{\mathrm{a}}$ & $(.20)^{\mathrm{a}}$ & $(.14)^{a}$ \\
\hline 2 & 2.55 & 2.38 & 2.18 & 4.38 & 4.29 & 4.28 & 4.10 \\
\hline Mid-level adjustment (32.6\%) & $(.19)^{\mathrm{b}}$ & $(.15)^{\mathrm{b}}$ & $(.16)^{\mathrm{b}}$ & $(.12)^{\mathrm{b}}$ & $(.14)^{\mathrm{b}}$ & $(.18)^{\mathrm{b}}$ & $(.13)^{\mathrm{b}}$ \\
\hline 3 & 1.64 & 1.38 & 1.29 & 4.98 & 5.21 & 5.11 & 4.91 \\
\hline High-level adjustment (55.6\%) & $(.08)^{\mathrm{c}}$ & $(.08)^{\mathrm{c}}$ & $(.07)^{\mathrm{c}}$ & $(.07)^{\mathrm{c}}$ & $(.08)^{\mathrm{c}}$ & $(.08)^{\mathrm{c}}$ & $(.07)^{\mathrm{c}}$ \\
\hline
\end{tabular}

Note. $N=144$. Different subscript letters within columns were significantly different from one another according to the wald test.

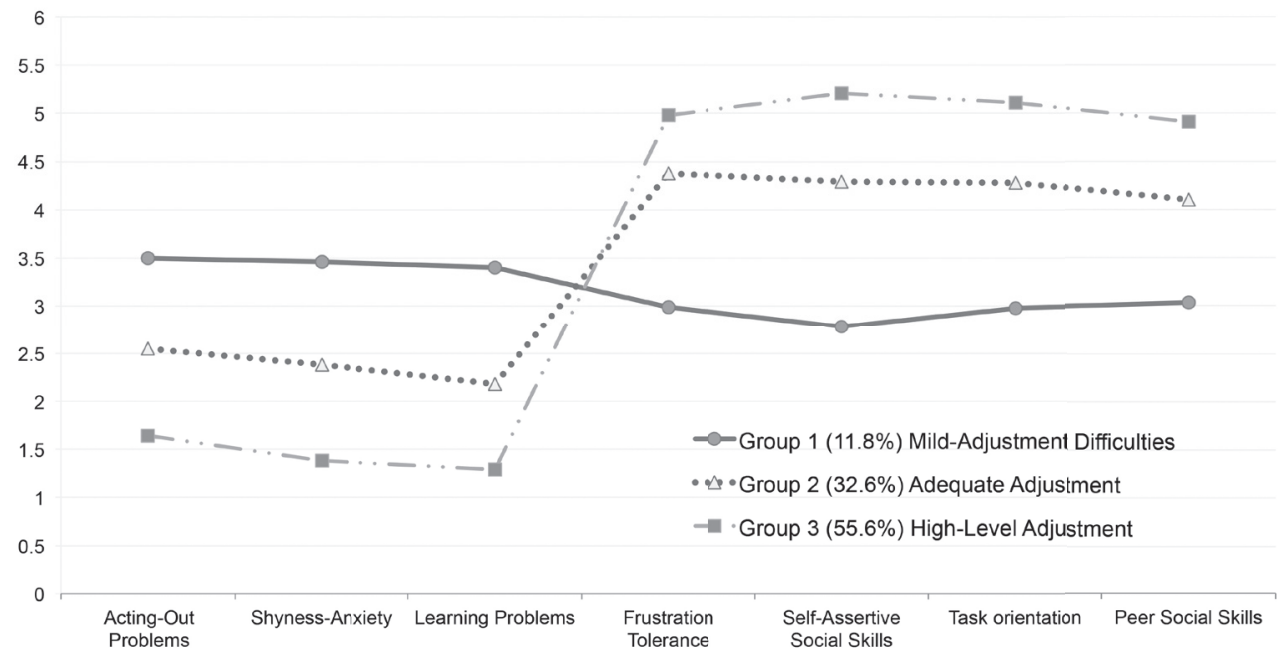

Figure 1. Latent profiles of school adjustment.

Table 4

Predicting Factors of the Latent Profile Classifications

\begin{tabular}{lccc}
\hline & Group 1a vs. Group 2 & Group 1a vs. Group 3 & Group 2a vs. Group 3 \\
\cline { 2 - 4 } \multicolumn{1}{c}{ Predicting factors } & $B(S E)$ & $B(S E)$ & $B(S E)$ \\
\hline Parenting efficacy & $.94(1.10)$ & $1.47(1.21)$ & $.53(.86)$ \\
Psychological expectations for children's education & $-.02(.54)$ & $-.14(.50)$ & $-.11(.45)$ \\
Educational support activities at home & $.34(.72)$ & $.36(.70)$ & $.03(.41)$ \\
Private education offering & $-.50(.90)$ & $1.46(.64)$ & $.81(.65)$ \\
Positive teacher-mother relationships & $.36(.52)$ & $.71(.51)$ &
\end{tabular}

Note. $N=144$. Group 1 = mild-adjustment difficulties; Group 2 = adequate adjustment; Group 3 = high-level adjustment; a = reference group. ${ }^{* *} p<.01 .{ }^{* * *} p<.001$.

저 경미한 적응 어려움형(집단 1)과 안정적 적응형(집단 2) 간 및 안정적 적응형(집단 2)과 고수준 적응형(집단 3) 간의 차이 를 살펴본 결과, 예측요인이 모두 통계적으로 유의한 영향을 미치지 않았다. 그러나 경미한 적응 어려움(집단 1)과 고수준
적응형(집단 3) 간의 차이에서 양육역량 $(B=1.47, p<.01)$, 가 정 내 자녀교육지원 활동 $(B=2.36, p<.001)$ 및 교사-학부모 관 계 $(B=1.46, p<.01)$ 는 통계적으로 유의한 영향을 미쳤다. 즉, 어머니의 양육역량이 높고, 어머니가 자녀에게 가정 내 교육 
지원 활동을 더 많이 제공하고, 담임교사와 관계가 좋을수록 아동이 경미한 학교적응 어려움보다 고수준 적응형에 속할 가 능성이 더 높았다.

\section{Discussion}

이 연구는 본격적인 공교육을 경험하는 초등학교 1학년 아동 의 도전적인 과업인 학교적응에 주목하여 아동의 학교적응의 유형을 확인하고자 하였다. 나아가 아동의 건강한 발달과 긍 정적 적응을 지원하기 위한 학부모로서 어머니의 교육 참여 요인으로 양육역량, 자녀교육에 대한 심리적 기대, 가정 내 교 육지원 활동, 사교육 지원 및 교사-학부모 관계를 구체적인 예 측요인으로 상정하여 아동의 학교적응 유형에 미치는 영향력 을 살펴보았다. 연구 결과는 다음과 같다.

첫째, 초등학교 1학년 아동의 학교적응의 유형은 '경미한 적응 어려움형(11.8\%)', '안정적 적응형(32.6\%)' 및 '고수준 적 응형(55.6\%)'으로 구분되었다. 각 유형에서 학교적응 하위요 인의 평균이 유의하게 다르다는 결과는 초등학교 1 학년 아동 의 학교적응이 하위요인에 따라 이질적인 유형으로 구분될 수 있음을 보여준다. 특히 이 연구에서는 아동의 학교적응을 긍 정적 지표와 부정적 지표의 총 일곱 개의 하위요인으로 나누 어 상세하게 살펴보았다는 데 의의가 있다. 아동 개인의 특성 에 따라 긍정적 또는 부정적 지표의 준거로서 학교적응 하위 요인이 다양하게 나타났는데 특히 적응과 부적응의 방향성에 따라 아동의 학교적응 유형이 구분될 수 있음을 확인하였다. 즉, 부정적 지표인 외현화 행동, 수줍음/불안, 학습문제가 긍 정적 학교적응 지표인 좌절인내, 자기주장적 사회기술, 과제 지향 및 또래관계기술보다 높을 경우 적응 어려움형으로, 이 와 반대일 경우 적응형으로 이질적으로 구분되었다.

나아가 초등학교 1학년 아동 중 적응에 경미한 어려움을 겪 는 아동의 비율이 안정적으로 적응하거나 높은 수준에서 적응 을 보이는 아동보다 낮아 대다수의 아동이 초등학교로의 전이 를 경험하면서 학교 환경에 중상위 수준으로 적응하고 있는 것으로 나타났다. 이러한 결과는 초등학교 저학년 아동의 학 교적응을 유형화한 국내·외 연구(Goh \& Jeon, 2020; Mindrila, 2016)와 맥을 같이하는 것이다. 즉, 아동의 초등학교 입학이 생애 초기의 큰 환경적 변화로서 긴장과 불안을 경험할 수 있 음(Jeong \& Park, 2017)에도 불구하고, 이들의 적응이 우려할 만한 수준이 아님을 실증적으로 확인하였다는 데 의의가 있 다. 그러나 이 연구에서 사용한 패널 조사의 시점이 아동이 가
장 적응의 어려움을 보일 수 있는 취약한 시기인 첫 학기 즉, 상반기를 경험하고 난 후인 8월로, 한 학기를 보내면서 이들이 경험한 어려움이 일정 수준 완화되었기 때문이라 볼 수 있다. 그럼에도 불구하고 일부 아동의 경우 경미하게 적응의 어려움 을 경험하였다는 데 주목하여 이들을 대상으로 학교적응의 변 화 양상을 지속적으로 모니터링 할 필요가 있을 것이다.

둘째, 초등학교 1학년 아동의 학교적응 유형에 미치는 어 머니의 교육 참여 요인의 영향력을 확인한 결과, 경미한 적응 어려움형과 고수준 적응형 간에 양육역량, 가정 내 자녀교육 지원 활동 및 교사-학부모 관계가 유의한 영향을 미쳤다. 먼저 어머니의 양육역량이 높을수록 경미한 적응 어려움형보다 고 수준 적응형에 속할 가능성이 더 높았다. 이는 어머니의 역할 수행 및 적응에 관한 지표로서 지식적, 정의적, 실천적 양육 특 성을 아우르는 종합적인 양육역량이 아동의 학교적응 유형에 미치는 영향을 확인한 결과로 초등학교 전이기 자녀를 둔 어 머니의 양육역량의 하위유지집단과 중상위유지집단 간 및 급 감소집단과 중상위 유지집단 간에 자녀의 학교적응에 통계적 으로 유의한 차이가 있음을 보인 Jung 등(2019)과 유사한 맥락 에서 해석될 수 있다. 즉, 자녀의 초등학교 입학과 더불어 학부 모로서의 역할 수행 및 적응 수준이 높은 어머니의 경우 새롭 게 부가된 역할 및 적응의 요구에 의연하게 대처하고, 효율적 인 자녀 양육을 위한 심리적인 안정을 유지하여 아동의 학교 적응에도 긍정적인 영향을 미친 것이라 추론해 볼 수 있다.

또한 어머니의 가정에서의 교육지원 활동과 교사-학부모 관계의 수준이 높을수록 아동의 학교적응은 경미한 적응 어려 움형보다 고수준 적응형에 속할 가능성이 더 높았다. 즉, 가정 내에서 자녀의 교육지원을 위해 학습에 적절한 환경을 제공하 거나, 학습 분위기를 조성하고, 직접 학습을 지도하며, 다양한 교육 관련 정보를 수집하고, 경험을 제공하는 등 자녀 교육을 지원하기 위해 어머니가 주체적인 역할을 하고, 교사와 학부 모 간 협력적인 관계를 보일수록 학령초기 아동이 학교에 더 잘 적응함을 보였다. 이는 자녀교육을 위해 제공되는 어머니 의 가정 내 교육지원 활동과 교사-학부모 질적 관계가 아동의 학교적응을 높이는 데 유의한 역할을 한 것으로, 초등학생이 지각하는 부모의 교육지원 행동이 자신에게 더 긍정적인 도움 이 된다고 보고한 Chun과 Chun (2016)과 맥락을 같이하는 것 이다. 또한 신뢰, 민감성 및 평등한 관계 속에서 구축된 건강한 교사와 학부모 간의 관계가 학교 내 교육의 주체인 아동의 긍 정적 발달과 원활한 학교적응에 기여함을 보고한 선행연구(E. M. Kim et al., 2013; Kohl et al., 2000; Santiago et al., 2016)와도 일치하는 결과라 볼 수 있다. 
특히 자녀의 초등학교 입학은 아동이 학교라는 새로운 환 경에 적응하는 것뿐만 아니라 가족 구성원에게도 자원봉사, 교육기부, 운영위원회 및 학부모회 활동 등 학부모로서의 역 할에 따른 참여가 요구된다는 점(Kwon \& Lee, 2019)에서 이 연구는 학부모를 대상으로 경험적 연구 결과를 도출하였다는 데 의미가 있다. 또한 아동의 학교적응 유형에 미치는 학부모 로서 어머니의 교육 참여 예측요인을 체계적으로 검토하여 그 중요성을 부각시켰다는 데 의의가 있다. 다시 말해, 이 연구는 자녀의 학교적응과 관련하여 학부모로서 자녀의 교육 참여를 이해하고, 나아가 학부모로서의 역할에 따른 실질적인 행동적 참여가 아동의 학교적응을 위한 가정 맥락 내 보호 요인으로 써 중요한 역할을 함을 시사한다. 이에 학령초기 아동의 학교 적응을 위한 교육 참여자로서 가정 내 학부모와 학교 간 연계 의 필요성을 제시하며, 가정에서부터 적절한 물리적 교육 환 경을 구성하고, 아동의 학교적응을 도울 수 있는 양질의 교육 지원 활동을 제공하고 지원할 수 있도록 구체적인 학부모 교 육 프로그램을 제공하는 방안을 마련할 필요가 있다. 이처럼 학령초기 자녀를 둔 학부모의 교육지원이 중요하고, 참여의 질을 향상시키려는 노력이 필요하지만 자녀를 위한 학부모의 교육참여가 이들에게 지나친 부담으로 작용하지 않도록 세심 한 교육현장의 배려 역시 필요할 것이다. 자녀가 초등학교에 입학한 후 특히 학부모는 자녀의 학교적응과 관련하여 불안 과 걱정으로 무리해서라도 자녀의 교육과 관련된 활동에 참여 하는 경향(Kwon \& Lee, 2019)을 보일 수 있기 때문이다. 나아 가 학교 맥락 내에서 학부모 교육 참여의 관계적 측면에서의 교사와의 유대감을 높일 수 있는 방안을 적극적으로 모색해 야 할 것이다. 면대면 또는 비대면 상담은 학교와 학부모 간의 의사소통의 한 유형으로써 아동의 건강한 성장을 위해서 필 수적이다(E. Kim \& Lee, 2016). 그러나 현재 학교 맥락 내 교사 의 상담은 주로 교사 주도로 일어나고, 아동의 학교생활 문제 를 주로 다루고 있다(J. Y. Kim \& Lee, 2020)는 데 교사와 학부 모 간의 정서적 유대감을 쌓기에는 한계가 있다. 따라서 교사 와 학부모 모두 상담에 주도적으로 참여할 수 있고, 다양한 주 제로 상담의 접근성을 높일 수 있도록 전문상담교사를 배치하 여 활용하는 등 교육 현장에서 상담에 대한 교사와 학부모의 인식과 태도 개선을 위한 노력이 필요할 것이다.

마지막으로 이 연구의 제한점을 검토하고자 한다. 첫째, 이 연구는 학부모로서 어머니의 응답만을 제한적으로 활용하여 아버지의 특성을 직접 확인하지 못했다. 한국의 문화적 맥락 에서는 주로 어머니가 자녀교육의 실질적인 역할을 담당하지 만(M.-K. Lee, 2007), 점차 아버지의 자녀교육 참여에 대한 역
할의 중요성이 강조되고 있다. 이에 후속연구에서는 연구변인 에 대한 아버지 응답을 보충하여 수집하고, 이를 확장하여 아 동의 학교적응에 미치는 효과를 확인한다면 자녀의 발달에 미 치는 학부모 역할에 대한 이해의 폭을 넓히는 데 기여할 것이 다. 둘째, 아동의 학교적응을 초등학교 1학년에 한정하여 살펴 보았다는 데 한계가 있다. 학부모의 교육 참여율과 참여 유형 은 학년에 따라 상의하게 나타날 수 있음(Kwon \& Lee, 2019) 에 근거하여 초등학교 전 과정에서 아동의 종단적 학교적응 의 변화 양상을 확인하고, 어머니의 학교 교육 참여와의 관련 성을 장기적으로 확장하여 살펴본다면 두 변인간 보다 풍부한 논의가 가능할 것이다. 셋째, 적은 수의 제한된 표본의 크기에 도 불구하고 이 연구의 가설을 검증하는 데 통계적으로 무리 는 없었지만 후속연구에서는 대규모 자료를 활용하거나 표본 수를 충분히 확보하여 유사한 결론이 도출되는지 확인한다면 아동의 학교적응 유형화와 이에 미치는 학부모로서 어머니의 교육 참여 요인의 영향력에 대한 연구의 타당도를 높이는 데 도움이 될 것이다.

\section{Conflict of Interest}

No potential conflict of interest relevant to this article was reported.

\section{Ethics Statement}

All procedures of this research were reviewed by IRB (1702/001005).

\section{References}

\section{In English}

Anderson, K. J., \& Minke, K. M. (2007). Parent involvement in education: Toward and understanding of parents' decision making. The Journal of Educational Research, 100(5), 311323. doi:10.3200/JOER.100.5.311-323

Asparouhov, T., \& Muthén, B. (2014). Auxiliary variables in mixture modeling: Three-step approaches using Mplus. Structural Equation Modeling: A Multidisciplinary Journal, 21(3), 329-341. doi:10.1080/10705511.2014.915181 
Berlin, K. S., Williams, N. A., \& Parra, G. R. (2014). An introduction to latent variable mixture modeling (part 1): Overview and cross-sectional latent class and latent profile analysis. Journal of Pediatric Psychology, 39(2), 174-187. doi:10.1093/jpepsy/jst084

Berns, R. M. (2015). Child, family, school, community: Socialization and support (10th ed.). Boston, MA: Cengage Learning.

Bronfenbrenner, U. (1979). The ecology of human development: Experiment by nature and design. Cambridge, MA: Harvard University Press.

Clarke, B. L., Sheridan, S. M., \& Woods, K. E. (2009). Elements of healthy family-school relationships. In S. L. Christenson \& A. L. Reschly (Eds.), Handbook of school-family partnerships (pp. 61-79). London: Routledge.

Correia, K., \& Marques-Pinto, A. (2016). Adaptation in the transition to school: Perspective of parents, preschool and primary school teachers. Educational Research, 58(3), 247-264. doi:10.1080/0 0131881.2016.1200255

Hightower, A. D., Work, W. C., Cowen, E. L., Lotyczewski, B., Spinell, A. P., Guare, J. C., \& Rohrbeck, C. A. (1986). The teacher-child rating scale: A brief objective measure of elementary children's school problem behaviors and competencies. School Psychology Review, 15(3), 339-409. do i: $10.1080 / 02796015.1986 .12085242$

Hong, S., Malik, M. L., \& Lee, M.-K. (2003). Testing configural, metric, scalar, and latent mean invariance across genders in sociotropy and autonomy using a non-western sample. Educational and Psychological Measurement, 63(4), 636-654. doi:10.1177/0013164403251332

Hoover-Dempsey, K. V., \& Sandler, H. M. (1997). Why do parents become involved in their children's education? Review of Educational Research, 67(1), 3-42. doi:10.3102/0034654 3067001003

Hoover-Dempsey, K. V., Walker, J. M., Sandler, H. M., Whetsel, D., Green, C. L., Wilkins, A. S., \& Closson, K. E. (2005). Why do parents become involved? Research findings and implications. The Elementary School Journal, 106(2), 105130. doi:10.1086/499194

Kim, E. M., Sheridan, S. M., Kwon, K., \& Koziol, N. (2013). Parent beliefs and children's social-behavioral functioning: The mediating role of parent-teacher relationship. Journal of School Psychology, 51(2), 175-185. doi:10.1016/j.jsp.2013. 01.003

Kohl, G. O., Lengua, L. J., \& McMahon, R. J. (2000). Parent involvement in school: Conceptualizing multiple dimensions and their relations with family and demographic risk factors. Journal of School Psychology, 38(6), 501-523. doi:10.1016/ S0022-4405(00)00050-9

Lanza, S. T., Tan, X., \& Bray, B. C. (2013). Latent class analysis with distal outcomes: A flexible model-based approach.
Structural Equation Modeling: A Multidisciplinary Journal, 20(1), 1-26. doi:10.1080/10705511.2013.742377

Marsh, H. W., Lüdtke, O., Trautwein, U., \& Morin, A. J. (2009). Classical latent profile analysis of academic self-concept dimensions: Synergy of person-and variable-centered approaches to theoretical models of self-concept. Structural Equation Modeling: A Multidisciplinary Journal, 16(2), 191225. doi:10.1080/10705510902751010

McCrae, J. S., Champman, M. V., \& Christ, S. L. (2006). Profile of children investigated for sexual abuse: Association with psychopathology symptoms and services. American Journal of Orthopsychiatry, 76(4), 468-481. doi:10.1037/00029432.76.4.468

Mindrila, D. L. (2016). A typology of child school behavior: Investigation using latent profile analysis and cluster analysis. Psychology in the Schools, 53(5), 471-487. doi:10.1002/ pits. 21917

Mplus (Version 8.0). [Computer software]. Los Angeles, CA: Muthén \& Muthén.

Muthén, B. (2004). Latent variable analysis: Growth mixture modeling and related techniques for longitudinal date. In D. Kaplan (Ed.), The SAGE handbook of quantitative methodology for the social science (pp. 345-368). Thousand Oaks, CA: Sage.

Roeser, R. W., \& Eccles, J. S. (1998). Adolescents' perceptions of middle school: Relation to longitudinal changes in academic and psychological adjustment. Journal of Research on Adolescence, 8(1), 123-158.

Santiago, R. T., Garbacz, S. A., Beattie, T., \& Moore, C. L. (2016). Parent-teacher relationships in elementary school: An examination of parent-teacher trust. Psychology in the Schools, 53(10), 1003-1017. doi:10.1002/pits.21971

Shumow, L., \& Lomax, R. (2002). Parental efficacy: Predictor of parenting behavior and adolescent outcomes. Parenting: Science and Practice, 2(2), 127-150. doi:10.1207/S15327922 PAR9292_03

Sturge-Apple, M. L., Davies, P. T., \& Cummings, E. M. (2010). Typologies of family functioning and children's adjustment during the early school years. Child Development, 81(4), 1320-1335. doi:10.1111/j.1467-8624.2010.01471.x

Vermunt, J. K. (2010). Latent class modeling with covariates: Two improved three-step approaches. Political Analysis, 18(4), 450-469. doi:10.1093/pan/mpq025

Weiten, W., \& Dunn, D. S. (2009). Psychology applied to modern life: Adjustment in the 21st century (9th ed.). Australia: Wadsworth Cengage Learning.

\section{In Korean}

Center for Family-School Partnership Policy Research at Seoul 
National University. (2019). Panel study on Korean parent educational involvement 2 nd survey [Data file and code book]. Retrieved from http://family-school.snu.ac.kr/

Chun, J., \& Chun, J. (2016). The effect of parental educational support on the mental health of elementary school students: The mediating effects of school life adjustment. The Journal of Korean Education, 43(2), 5-35.

Chung, H. (2002). Reliability and validity of a Korean version of the teacher-child rating scale. The Korean Journal of Developmental Psychology, 15(2), 73-88.

Chung, J. (2019). Factors affecting school adaptation of first-grade elementary school children of working mothers. Korean Journal of Human Ecology, 28(3), 185-199. doi:10.5934/ kjhe.2019.28.3.185

Chung, K.-S., \& Choi, E.-S. (2013). A study on the development of authentic parental competence scale for mothers with young children. The Journal of Korea Open Association for Early Childhood Education, 18(3), 225-257.

Chung, K.-S., Park, H.-K., \& Cha, J.-R. (2016). A validation study of a short version of the authentic parental/competence scale for mothers with young children. Journal of Early Childhood Education, 36(2), 535-560.

Goh, E. K., \& Jeon, H. J. (2020). Investigating predictors of first graders' school adjustment in Korean elementary school using latent profile analysis and machine learning. Korean Journal of Child Studies, 41(4), 75-90. doi: 10.5723/ kjcs.2020.41.4.75

Han, S. (2008). A cultural psychological suggestion for the educational circumstances of Korea. The Korean Journal of Culture and Social Issues, 14(1), 33-46.

Hong, Y.-J., \& Lee, K. (2020). Identifying the typology of changes in work-family conflict among working mothers with an early school-age child and examining antecedents and consequences. Korean Journal of Child Care and Education Policy, 14(1), 97-120. doi:10.5718/kcep.2020.14.1.97

Jang, H. J., \& Yun, E. J. (2014). The current status of parental capacity for children's happiness. Journal of Korean Child Care and Education, 10(2), 295-317. doi:10.14698/ jkcce.2014.10.2.295

Jeong, K., \& Park, C. (2017). Exploring viewpoints of transition to elementary school. Journal of Curriculum Integration, 11(4), 121-143.

Jung, J.-H., Hong, Y.-J., \& Lee, K. (2019). Identifying latent classes of the parenting efficacy changes among mothers having children in an elementary school transition and testing antecedents and consequences of the classes. The Korean Journal of the Human Development, 26(4), 115-138. doi:10.15284/kjhd.2019.26.4.115

Kim, C.-I., \& Kwon, Y.-J. (2018). The effects of mother's behavior control trajectory on school adjustment, studying ability and subjective happiness for children. The Journal of Child Education, 27(3), 207-221. doi:10.17643/KJCE.2018. 27.3.11

Kim, E. (2018). Exploring effective variables for school adjustment in the first grade. The Korean Journal of Applied Developmental Psychology, 7(1), 19-34. doi:10.22839/adp. 2018.7.1.19

Kim, E., \& Lee, K. (2016). Study on actual condition and activation of the communication between school and parents by parents of elementary, middle, and high school student: Focusing on parent involvement model schools. Journal of Learner-Centered Curriculum and Instruction, 16(7), 27-49.

Kim, J. Y., \& Lee, K. (2020). The effects of mother's educational involvement on first-grader's school adjustment: The interactive effects of teacher-parents relationship. Journal of Parent Education, 12(1), 81-103. doi:10.36431/JPE.12.1.5

Kwon, S., \& Lee, J. (2019). Typology and changes of mothers' educational involvement in Korea during the first two years of elementary school: A latent transition analysis. The Korean Journal of the Human Development, 26(4), 1-25. doi:10.15284/kjhd.2019.26.4.1

Lee, M.-K. (2007). A discourse on education: An analysis of the attitude of middle-class Korean mothers on the education of their children. Korean Journal of Sociology of Education, 17(3), 159-181. doi:10.32465/ksocio.2007.17.3.007

Lee, S. H., \& Hwang, H. J. (2014). Influence of children's gender and surrounding's variables on school readiness: Based on educational level of parents, educational participation of mother, teaching method of teacher and literacy conditions of home and class. Journal of Childcare \& Education, 10(4), 177-203. doi:10.14698/jkcce.2014.10.4.177

Lim, S. (2001). A structural analysis of determinants of teachers' job involvement. The Korean Journal of Educational Psychology, 15(4), 441-462.

Min, M.-H. (2018). The effects of mother's warmth parenting, control parenting and child executive function difficulty on the school adjustment in the first grade. Journal of Early Childhood Education \& Educare Welfare, 22(3), 91-121.

Shim, M. O. (2003). Parent educational supporting activities for their children. The Journal of Elementary Education, 16(2), 333-358.

Seol, K. O., Kyeong, Y., \& Park, J. E. (2015). Mother's child-based self-worth, parenting and psychological adjustment of children. Korean Journal of Psychology: General, 34(1), 109131.

Woo, J. Y., \& Shim, M. K. (2019). The effect of parenting sensibility and preschool social skills on school adjustment in early school age: Mediating effect on parenting efficacy and child's happiness. Korean Journal of Child Education and Care, 19(4), 1-13. doi:10.21213/kjcec.2019.19.4.1 


\section{ORCID}

Yea-Ji Hong http://orcid.org/0000-0003-4183-5373

Yujin Jang http://orcid.org/0000-0002-5804-3391

Kangyi Lee http://orcid.org/0000-0002-1193-5771

Received December 31, 2020

Revision received February 15, 2021

Accepted April 9, 2021 